\title{
Research On The Popularization And Application Of Distributed Combined Cool, Heat And Power Supply
}

\author{
Niu Meng ${ }^{1, \text { a }}$, Zhao Bo ${ }^{1}$, Xiao $\mathrm{Yu}^{1}$ and Qi Yan ${ }^{2}$ \\ ${ }^{1}$ Global Energy Interconnection Research Institute, Future Technology Park, Changping District, \\ Beijing 102200, P. R. China \\ ${ }^{2}$ Tianjin Electric Power Company State Grid Corporation of China, Wujing load No. 39, Hebei District, \\ Tianjin 300000, P. R. China \\ aemail : niumeng0110@139.com
}

Keywords: Combined Cool, Heat and Power Supply; Distribute; environmental benefit; coordinative operation; Value added services

Abstract. With the continuous growth of energy load, causing environmental problems have become increasingly prominent. Nitrogen oxides and sulfur dioxide and other gases cause serious environmental pollution. Harm of carbon dioxide, soot and heavy metals is increasingly prominent. Therefore energy conservation and environmental protection are without delayed. Distributed Combined Cool, Heat and Power Supply (DCCHP) is a system based on the basis of energy cascade utilization. The generation system has natural gas as primary energy to produce heat, electricity, cold, heat and power. Effectively improve the energy efficiency. This paper analyzes benefits of the distributed DCCHP system and relationships with other economic entities. Based on this analysis of the application of the existing problems, the solution is given.

\section{Introduction}

With the continuous development of social economy, energy load is growing. At the same time, a large number of developments and application of fossil energy caused tremendous damage of the Earth's environment. And it also puts pressure on the sustainability of energy. With awareness of environmental quality requirements continuing to increase, as well as the deepening of sustainable development strategy, improving energy efficiency and reducing harmful gas emissions have become a top priority of energy use. Efficient use of energy is the prerequisite that achieves economic and environmental coordinated development ${ }^{[1]}$.

The energy we need includes electric power, heat and cooling loads. With the traditional energy use patterns, the heat of fossil energy will transform into electricity. And then the electrical energy will transform into different types of cold or heat what we need. All of these caused a lot of waste. For the purposes of power system, the heat engine only can generate part of heat in the combustion of fossil energy into electrical energy. And the other heat is released into the environment in general. But only about one-third heating value of the fuel can be converted into electrical energy. For cooling, heating systems, winter and summer load surge intensified pressure of power grid. In order to meet rapidly increasing Di electricity load, Power plants must increase generating units, which directly leads to more waste heat can be used. Then more waste of energy is resulted.

While the power plant operated and the power generated, waste heat from power generation is recycled by DCCHP system. Then it give users the heating and cooling to achieve the energy cascade utilization. Comprehensive energy efficiency can be up to $75 \%-90 \%{ }^{[2]}$.

\section{Benefit analysis of DCCHP.}

Regeneration's energy use can achieve cascade utilization and transform energy by closing to the user. It avoids power transmission losses and heat loss caused by long-distance power transmission and greatly improves the efficiency of energy use. There are cities such as Shanghai, Beijing and others have begun to make the regenerations as a long-term policy which is supported by the project. DCCHP system takes the benefits that are divided into: environmental and economic benefits. 


\section{A.Environmental Benefits}

a. The comparison between traditional energy supply mode and DCCHP. With the global warming and environmental pressures increasing, that the energy system reduces $\mathrm{CO} 2, \mathrm{SO} 2, \mathrm{NOX}$ and dust emissions and other pollutants is the embodiment of its environmental value.

Distributed heating and power energy system make natural gas and other clean energy sources to replace traditional fossil energy. It can reduce pollutant emissions. According to coal-fired power plant emissions rate, we contrast the affect of the coal-fired power generation and natural gas on the environment as table 1[6].

Table 1 Comparison of pollutants emissions from Coal-fired power plant and Gas-fired power plant

\begin{tabular}{rccc}
\hline $\begin{array}{c}\text { Pollutants } \\
\text { Emissions }\end{array}$ & $\begin{array}{c}\text { Coal-fired power plant } \\
g \cdot(\mathrm{kw} \cdot \mathrm{h})-1\end{array}$ & $\begin{array}{c}\text { Gas-fired power plant } \\
g \cdot(\mathrm{kw} \cdot \mathrm{h})-1\end{array}$ & $\begin{array}{c}\text { Percentage } \\
\text { emissions } \%\end{array}$ \\
\hline SO2 & 8.556 & 0.0023 & 0.027 \\
NOx & 3.803 & 1.24 & 32.61 \\
CO2 & 822.802 & 402 & 48.86 \\
CO & 0.124 & 0 & 0 \\
TSP & 0.1901 & 0.0476 & 25.04 \\
Gray & 52.287 & 0 & 0 \\
Dregs & 14.26 & 0 & 0 \\
\hline
\end{tabular}

Visibly, compared with coal-fired power, the impact of natural gas on the environment is relatively small. Its SO2 and solid waste was almost zero. The reduction of greenhouse gas (GHG) was $1 / 2$ and NOx $2 / 3$, TSP 3/4. Also from the ecological benefits, the reduction of its area was $1 / 2$ and water consumption 2/3. Experts also calculated that the environmental value of natural gas is about 8.9639 yuan $\bullet(\mathrm{kW} \bullet \mathrm{h})-1$. If other renewable energy sources are included in the heating and power photovoltaic energy systems, the system will further reduce pollutant emissions.

b. Environmental benefit analysis model

(1) In the traditional energy supply mode, the cooling, heating and power supplies are carried out separately. Based on pollutant discharge coefficient and the unit of pollutant emission control expense, environmental cost calculation models can be got.

$$
\begin{aligned}
& \mathrm{C}=\mathrm{C}_{\mathrm{E}}+\mathrm{C}_{\mathrm{H}}+\mathrm{C}_{\mathrm{C}} \\
& C_{\mathrm{E}}=\left(e_{\mathrm{CO}_{2}} \times C_{\mathrm{CO}_{2}}+e_{\mathrm{SO}_{2}} \times C_{\mathrm{SO}_{2}}+e_{\mathrm{NO}_{x}} \times C_{\mathrm{NO}_{x}}+e_{\mathrm{PM}} \times C_{\mathrm{PM}}\right) \times Q_{E} \\
& C_{\mathrm{H}}=\left(e_{\mathrm{CO}_{2}}^{\prime} \times C_{\mathrm{CO}_{2}}+e_{\mathrm{SO}_{2}}^{\prime} \times C_{\mathrm{SO}_{2}}+e_{\mathrm{NO}_{x}}^{\prime} \times C_{\mathrm{NO}_{x}}+e_{P M}^{\prime} \times C_{P M}\right) \times Q_{\mathrm{H}} \\
& C_{\mathrm{C}}=\left(e_{\mathrm{CO}_{2}} \times C_{\mathrm{CO}_{2}}+e_{\mathrm{SO}_{2}} \times C_{\mathrm{SO}_{2}}+e_{\mathrm{NO}_{x}} \times C_{\mathrm{NO}_{x}}+e_{\mathrm{PM}} \times C_{P M}\right) \times Q_{C} / \alpha_{C}
\end{aligned}
$$

In this formula, $C_{E}, C_{H}, C_{C}$ are environmental cost of power, heating and cooling supply; $e_{\mathrm{CO}_{2}} 、 e_{\mathrm{SO}_{2}} 、 e_{\mathrm{NO}_{x}} 、 e_{\mathrm{PM}}$ are unit generating capacity average emissions of $\mathrm{CO} 2, \mathrm{SO} 2, \mathrm{NOx}$ and solid particulate; $e_{\mathrm{CO}_{2}}^{\prime} 、 e_{\mathrm{SO}_{2}}^{\prime} 、 e_{\mathrm{NO}_{x}}^{\prime} 、 e_{\mathrm{PM}}^{\prime}$ are unit heating supply average emissions of $\mathrm{CO} 2, \mathrm{SO} 2, \mathrm{NOx}$ and solid particulate; $C_{\mathrm{CO}_{2}} 、 C_{\mathrm{SO}_{2}} 、 C_{\mathrm{NO}_{x}} 、 C_{p m}$ are unit mass pollutant control expense costs of CO2, SO2, NOx, solid particulate; $Q_{E} 、 Q_{H} 、 Q_{C}$ are quantity demanded for electricity, heat and cold; $\alpha_{C}$ is the electric refrigeration efficiency.

(2) Through absorbing waste heat, from the generating process, to supply heating and cooling , DCCHP realize cascade utilization of energy, improve the utilization efficiency of the energy resources. At present, DCCHP is generally used in the operation mode, which is follow the heating demand determines the amount of power generation. There is environmental cost calculation model of DCCHP. 


$$
\begin{aligned}
& C^{\prime}=C_{E}^{\prime}+C_{H}^{\prime}+C_{C}^{\prime} \\
& C_{E}^{\prime}=\left(e_{\mathrm{CO}_{2}} \times C_{\mathrm{CO}_{2}}+e_{\mathrm{SO}_{2}} \times C_{\mathrm{SO}_{2}}+e_{\mathrm{NO}_{x}} \times C_{\mathrm{NO}_{x}}+e_{P M} \times C_{P M}\right) \times Q_{E}^{\prime} \\
& C_{H}^{\prime}=\left(e_{\mathrm{CO}_{2}}^{\prime \prime} \times C_{\mathrm{CO}_{2}}+e_{\mathrm{SO}_{2}}^{\prime \prime} \times C_{\mathrm{SO}_{2}}+e_{\mathrm{NO}_{x}}^{\prime \prime} \times C_{\mathrm{NO}_{x}}+e_{P M}^{\prime \prime} \times C_{P M}\right) \times\left(Q_{H}+Q_{C}^{\prime \prime} / \beta_{C}\right) \\
& C_{C}^{\prime}=\left(e_{\mathrm{CO}_{2}} \times C_{\mathrm{CO}_{2}}+e_{\mathrm{SO}_{2}} \times C_{\mathrm{SO}_{2}}+e_{\mathrm{NO}_{x}} \times C_{\mathrm{NO}_{x}}+e_{P M} \times C_{P M}\right) \times Q_{C}^{\prime} / \alpha_{C} \\
& Q_{E}=Q_{E}^{\prime}+Q_{E}^{\prime \prime}+Q_{E}^{\prime \prime \prime} \\
& Q_{C}=Q_{C}^{\prime}+Q_{C}^{\prime \prime}
\end{aligned}
$$

In this formula, $C_{E}^{\prime} 、 C_{H}^{\prime} 、 C_{C}^{\prime}$ are DCCHP mode environmental costs of power, heating and cooling supply; $Q_{E}^{\prime} 、 Q_{E}^{\prime \prime} 、 Q_{E}^{\prime \prime \prime}$ are the purchased power and natural gas power generation and distributed energy generation; $e_{\mathrm{CO}_{2}}^{\prime \prime}, e_{\mathrm{SO}_{2}}^{\prime \prime} 、 e_{\mathrm{NO}_{x}}^{\prime \prime} 、 e_{P M}^{\prime \prime}$ are gas turbine unit generating capacity average emissions of $\mathrm{CO} 2$, SO2, NOx and solid particulate;

$Q_{C}^{\prime} 、 Q_{C}^{\prime \prime}$ are purchased electric refrigeration and gas waste heat refrigeration. $\beta_{C}$ is the efficiency of absorption refrigerating.

(3) Through the above analysis, the formula of DCCHP's environmental benefits is got. $\Delta C=C-C^{\prime}$

\section{B. Economic Benefits}

a. Reducing the cost of transmission and distribution sectors. DCCHP system closing to the load center gets on energy conversion, its the "local production, local consumptive" model will bring significant economic benefits to the relevant economic entities. For example, the price of centralized power production of electricity in the wholesale electricity market is $0.12-0.18$ yuan / $\mathrm{kWh}$. When the power reaches the end user's retail, the price will reach $0.48-0.72$ yuan / $\mathrm{kWh}$. Enhance the price of two links is mainly because electricity power from production process to consumption process increase costs of transmission and distribution, while the DCCHP system avoids power transmission losses and heat loss caused by the long-distance transmission and reducing energy expenses of end users.

b. Participation in peak load periods peaking. In the peak load period, DCCHP systems run at full capacity to have adequate supply of hot and cold load in the region and reduce power consumption. Improving power generation efficiency and economic benefits of large power plants through load shifting manner to run complementarily with large power grid to assist large power grid shifting peak load, reducing peak load difference of the large power grid, improving the impact of dynamic load changes on voltage stability.

\section{Problem analysis}

\section{A. Improving service price system to protect the main parties mutually beneficial}

Running in conjunction with the power system in the process, DCCHP system to provide technical support services for the power system. Compared with the purchase and sales transactions, technical support services are more difficult to measure quantitatively. And natural monopoly characteristics of the electric power industry easily lead to information system operation and process transactions related subjects' asymmetry. We cannot rule out the possibility of unequal power distribution companies to give rewards. Reasonably price provided for technical support services of DCCHP system will facilitate mutually beneficial to distribution companies, hot and cold operation of the main body as well as electric power users. It can promote the optimization of operational and business DCCHP system to achieve its important energy saving values.

\section{B. Subsidies according to their environmental values}

Compared with conventional energy supply systems, distributed energy station construction has higher initial investment costs and long payback period. And energy supply systems are complexity, comprehensive. They have high operating costs. Therefore, "not saving money" problem exists. In 
order to encourage the development of DCCHP, we should allow it obtain social benefits adequately compensated in environmental protection.

\section{New business model of DCCHP}

Based on the value analysis of DCCHP, this paper puts forward a new business model.

\section{A. The approach of new business model}

a. Direct Power-Purchase. Through negotiated and bidding way, DCCHP can trade with users directly. And electricity prices can be adjusted according to the supply and demand.

b. Ancillary service. DCCHP can participate in large power grid peak load shifting, and provide ancillary service.

c. Value added services. Regional energy station access to the large power grid helps to reduce the load curve fluctuations.

d. Environmental transactions. DCCHP play a significant role in improving energy efficiency and reducing emissions of pollutants. The environmental value of DCCHP should be reflected.

\section{B. New business model revenue analysis}

$$
R_{\text {new }}=R_{\text {load }}+R_{\text {engine-a }}+R_{\text {engine-c }}+R_{\text {AGC }}+R_{\text {vas }}+R_{E P}
$$

In this formula, $R_{\text {new }}$ is the total revenue in the new business model; $R_{\text {load }}$ is the revenue of cold and heat supply; $R_{\text {engine-c }}$ is the revenue of direct power-purchase; $R_{\mathrm{AGC}}$ is the revenue of ancillary service; $R_{\text {vas }}$ is the revenue of value added services; $R_{E P}$ is the revenue of environmental transactions.

\section{Conclusion}

By comparing pollutant emission between traditional energy supply mode and DCCHP, it is proved that DCCHP has great environmental value. And in the process of the co-operation with the power system, DCCHP can provide Ancillary service for the grid, such as peak load shifting, voltage stability, reducing system losses and to ensure the quality of power supply and so on. Base on the value analysis of DCCHP, this paper presents some policy suggestions and a new business model.

\section{Acknowledgements}

Science and Technology Project of China State Grid Corp headquarters, Research and application of the key technology of CCHP optimization and adjustment, （SGTJDK00DWJS1500100）

\section{References}

[1] Zhou R, Ran X, Mao F, et al. Energy-Saving Coordinated Optimal Dispatch of Distributed Combined Cool, Heat and Power Supply[J]. Power System Technology, 2012, 36(6):8-14.

[2] Yan-Fei H U, Jing-Yi W U, Sheng L I. Optimal operation analysis of combined cooling heating and power(CCHP) system[J]. Journal of North China Electric Power University, 2010.

[3] Wei X, Jin J, Feng J. The environmental value of electricity from natural-gas-fired power plants[J]. Gas Turbine Technology, 2002.

[4] Xue-Hao H U. Development situation and grid-connection of distributed triple-generation in China[J]. Journlal of Shenyang Institute of Engineering, 2005.

[5] Huang J T, Feng Z P, Yuan J S. Economic analysis of distributed triple-generation system[J]. Journal of Shenyang Electric Power Institute, 2005.

[6] Zhou H, Environmental value of natural gas power generation[J]. Thermal Power Generation,2003. 